\title{
Pengembangan Media Pembelajaran Permainan Monopoli Asean untuk Meningkatkan Hasil Belajar Tema 1 Selamatkan Makhluk Hidup Pada Siswa Kelas 6 Sekolah Dasar
}

\section{Ganes Mahesti ${ }^{*}$, Henny Dewi Koeswanti ${ }^{2}$}

${ }^{12}$ Jurusan Pendidikan Guru Sekolah Dasar, Universitas Kristen Satya Wacana, Salatiga, Indonesia

\section{A R T I CLEINFO}

\section{Article history:}

Received 1 Januari 2021

Received in revised form 30 Januari 2021

Accepted 1 Maret 2021

Available online 8 April 2021

\section{Kata Kunci:}

game edukasi, android,

hasil belajar

Keywords: educational game, android, learning outcomes

\begin{abstract}
A B S T R A K
Masih banyak guru yang menggunakan metode ceramah dan kurangnya media pembelajaran yang menarik sehingga pembelajaran menjadi monoton dan membosankan. Tujuan dari penelitian ini yaitu untuk menganalisis tingkat validasi dari ahli materi dan ahli media. Jenis penelitian dan pengembangan media pembelajaran menggunakan metode Research and Development atau $(R \& D)$ dengan model pengembangan ADDIE yang memiliki lima tahapan yaitu analysis, design, development, implementation, evaluation. Instrumen yang digunakan untuk mengumpulkan data adalah kuesioner. Data untuk uji validasi ahli media dan validasi ahli materi dianalisis menggunakan teknik deskriptif presentase. Data hasil uji validasi ahli diperoleh sebagai berikut: (1) Penilaian yang diberikan oleh validator ahli media mmperoleh presentase sebesar $83 \%$ yang menunjukkan penilaian dengan kriteria sangat baik. (2) Penilaian yang diberikan oleh validator ahli materi mmperoleh presentase sebesar $78 \%$ yang mennjukkan penilaian dengan kriteria baik. Berdasarkan nilai yang diperoleh media pembelajaran Game Monopoli Asean untuk meningkatkan hasil belajar Tema 1 Selamatkan Makhluk Hidup pada Kelas 6 Sekolah Dasar dapat dikatakan sangat layak untuk digunakan. Implikasi penelitian ini yaitu media pembelajaran ini dapat diterapkan oleh guru untuk membantu siswa dalam belajar
\end{abstract}

\section{A B S T R A C T}

There are still many teachers who use the lecture method and the lack of attractive learning media so that learning becomes monotonous and boring. The purpose of this study is to analyze the level of validation of material experts and media experts. This type of research and development of learning media uses the Research and Development or (R\&D) method with the ADDIE development model which has five stages, namely analysis, design, development, implementation, evaluation. The instrument used to collect data was a questionnaire. The data for the media expert validation test and the material expert validation were analyzed using the percentage descriptive technique. The data from the expert validation test were obtained as follows: (1) The assessment given by the media expert validator obtained a percentage of $83 \%$ which indicated that the assessment was with very good criteria. (2) The assessment given by the material expert validator obtained a percentage of $78 \%$ which indicated that the assessment was with good criteria. Based on the value obtained, the Asean Monopoly Game learning media to improve learning outcomes Theme 1 Save Living Beings in Grade 6 Elementary School can be said to be very feasible to use. This research implies that this learning media can be applied by teachers to assist students in learning.

\section{Pendahuluan}

Perkembangan teknologi di era globalisasi saat ini telah mengambil perhatian penuh bagi masyarakat umum, tidak hanya anak muda, orang tua, bahkan peserta didik usia dini dan peserta didik usia Sekolah Dasar (SD) sudah terbiasa dengan perkembangan TIK yang begitu cepat. Salah satunya penggunaan android yang hampir semua orang punya dan pernah melihat ataupun 
memegang secara langsung (Muyaroah \& Fajartia, 2017; Noviar, 2016). Perkembangan teknologi sangat berpengaruh besar dalam kebiasaan setiap individu yang tentu saja memiliki dampak negatif dan juga dampak positif. Dengan adanya perkembangan teknologi memberikan jalan pintas yang mudah bagi setiap individu (Suryanda, Ernawati, \& Maulana, 2016; Wulandari, Sudatha, \& Simamora, 2020). Contohnya untuk menyapa saja tidak perlu harus bertemu secara langsung, dengan perkembangan teknologi kita dapat menyapa seseorang hanya dalam sebuah aplikasi yang berbasis android. Namun dengan adanya perkembangan teknologi terutama android dapat mengalihkan masyarakat sehingga kebiasaan yang bergantung dengan android. Masyarakat akan mendapatkan informasi hanya melalui android dan tidak merasa bosan jika di rumah saja karena melalui android masyarakat mendapatkan hiburan yang mengakibatkan perkembangan teknologi dapat mengambil perhatian penuh sehingga akan terjadi kemunduran bersosialisasi. Kemajuan teknologi harus diimbangi dengan pendidikan agar masyarakat tidak terlena dan dapat memanfaatkan teknologi dengan baik terutama peserta didik atau generasi bangsa (Fathoni, Utomo, Hangga, \& Pamungkas, 2018; Lubis \& Ikhsan, 2015).

Permasalahan di bidang pendidikan dalam perkembangan teknologi di era globalisasi ini salah satunya dengan perubahan kurikulum. Pada saat ini Indonesia telah menggunakan kurikulum 2013 dimana setiap perubahan kurikulum mempunyai tujuan untuk memajukan pendidikan di Indonesia yang sejalan dengan perkembangan teknologi (Nugraha, 2017; Sofyan, 2016). Kurikulum 2013 ini menggunakan pembelajaran tematik integratif pendekatan saintifik. Dalam pembelajaran tematik integratif, setiap kompetensi dari berbagai mata pelajaran di gabungkan ke dalam sebuah tema. Pembelajaran tematik integratif merupakan pendekatan pembelajaran dengan mengintegrasikan berbagai kompetensi dari berbagai mata pelajaran ke dalam tema. Mata pelajaran Pendidikan Agama dan budi pekerti dikecualikan untuk tidak menggunakan pembelajaran tematik integratif. Dengan demikian, pembelajarannya memberikan makna yang utuh kepada peserta didik. Hal ini sama dengan tantangan abad 21 yang menuntut adanya pemikiran yang berkualitas, sehingga dapat bersaing dengan pendidikan dunia (Mulyadin, 2016; Mustikaningrum, Pramusinta, Ayu, \& Umar, 2020). Maka dari itu, satuan pendidikan sebaiknya memberikan kesempatan kepada peserta didik untuk dapat mengembangkan kemampuan peserta didik. Salah satunya dengan merubah tata cara proses belajar mengajar yang sesuai dengan kurikulum 2013.

Dilansir dari Bank Dunia (World Bank) pada tahun 2018, kualitas pendidikan di Indonesia masih rendah, walaupun akses pendidikan untuk masyarakat sudah meningkat. Pendidikan di Indonesia masih rendah juga sejalan dengan hasil survei Programme for International Student Assessmen (PISA) 2018. Perolehan skor PISA pada tiga periode terakhir aitu (1) survei PISA 2009, Indonesia peringkat ke-57 dari 65 negara. (2) survei PISA 2012, Indonesia peringkat ke-64 dari 65 negara. (3) survei PISA 2015, Indonesia peringkat ke-64 dari 72 negara. (4) survei PISA 2018, Indonesia peringkat ke-74 dari 79 negara (Harususilo, 2019). Selain itu masih banyak siswa yang memilki nilai yang rendah terutama pada pelajaran tematik (Muskania, Badariah, \& Mansur, 2019; Qondias, Anu, \& Niftalia, 2016). Berdasarkan hasil observasi dan wawancara yang telah dilakukan dengan guru kelas 6 SD Negeri Salatiga 03, bahwa hasil belajar siswa terutama kelas 6 dalam pembelajaran tematik masih rendah. Hal ini disebabkan oleh beberapa faktor, salah satunya guru masih menggunakan metode ceramah dalam penyampaian informasi sehingga membuat siswa merasa bosan karena pembelajaran kurang menarik. Selain itu kurangnya media pembelajaran yang dapat membantu siswa. Guru hanya menerangkan materi pelajaran dan jarang menggunakan media pembelajaran. Hal ini yang menyebabkan siswa kesulitan dalam memahami materi tematik.

Faktor yang mempengaruhi keberhasilan pembelajaran adalah keterampilan guru dalam menyajikan materi. Penyajian materi yang tidak membosankan dan menarik dapat memberikan pengaruh positif terhadap peserta didik (Awaludin, Wibawa, \& Winarsih, 2020; Effendi \& Hendriyani, 2020). Selain penyajian materi, cara guru dalam mengajar juga diperlukan untuk mengatasi tantangan perkembangan jaman. Perubahan cara mengajar dapat dilihat dengan perubahan pendekatan pembelajaran tradisional yang menekankan pembeljajaran bersifat hafalan menjadi pembelajaran kontekstual. Selain itu media pembelajaran juga dapat membantu siswa dalam belajar karena siswa merasa tertarik (Hartini, Misbah, Dewantara, Oktovian, \& Aisyah, 2017; Wulandari et al., 2020). Berdasarkan masalah-masalah diatas, maka upaya untuk menanggulangi masalah dengan mengembangkan media yang ramah bagi ligkungan belajar dan sesuai dengan perkembangan TIK (teknologi, informasi, dan komunikasi). Produk inovatif ini berupa permainan monopoli. Kita dapat 
mengadaptasi permainan monopoli untuk menjadi sebuah media pembelajaran. Produk ini berupa aplikasi pembelajaran yang mengupas materi dengan permainan monopoli berbasis android.

Media pembelajaran merupakan alat atau perantara penyampaian informasi pembelajaran yang efektif untuk mencapai tujuan pembelajaran. Media pembelajaran dapat digunakan untuk menyalurkan pesan yang dapat membantu guru dalam menyampaikan materi sehingga tujuan pembelajaran dapat tercapai secara maksimal (Lestari, Negara, \& Ganing, 2017; Pramana, Jampel, \& Pudjawan, 2020; Tegeh, Simamora, \& Dwipayana, 2019). Kemampuan guru dalam merancang media yang menarik merupakan kunci dari keberhasilan proses belajar. Media pembelajaran sangat efektif digunakan untuk mencapai suatu tujuan pembelajaran. Dengan menggunakan media yang inovatif dapat memicu siswa untuk semangat belajar dan memotivasi siswa dapat lebih aktif di dalam proses belajar mengajar sehingga dapat meningkatkan hasil belajar siswa (Azimi, Rusilowati, \& Sulhadi, 2017; Mustofa \& Syafi'ah, 2018). Media dapat berupa sebuah permainan. Karena pada dasarnya peserta didik itu menyukai sebuah permainan, maka dari itu untuk menarik perhatian peserta didik agar menyukai suatu pembelajaan harus menggunakan media yang menarik, bisa juga dengan media yang bisa sekaligus dibuat dengan bermain. Siswa dapat belajar sambil bermain dapat sebagai alternatif belajar untuk menumbuhakan motivasi belajar peserta didik sehingga dapat lebih mudah utuk memahami materi dan bisa juga memperbaiki sikap siswa dalam kehidupan sehari-hari.

Penelitian yang dilakukan oleh Purbasari, Kahfi, \& Yunus (2013) menyatakna bahwa media pembelajaran berbasis adroid dapat membuat siswa tertarik dalam belajar. Penelitian yang dilakukan oleh Qumillaila, Susanti, \& Zulfiani (2017) media pembelajaran dapat memudahkan siswa dalam belajar karena sajiannya yang menarik. Penelitian yang dilakukan oleh Asnur \& Ambiyar (2018) juga menyatakan bahwa media pembelajaran dapat membantu siswa dalam belajar sehingga dapat meningkatkan hasil belajar siswa. Bentuk media pembelajaran harus sesuai dengan perkembangan zaman seperti yang sudah diketahui bahwa secara tidak langsung, semua dipaksa untuk menguasai TIK, termasuk instansi pendidikan agar pendidikan di Indonesia dapat bersaing di era global ini.

Permainan monopoli sangat cocok dengan peserta didik Sekolah Dasar (SD) karena pada dasarnya permainan merupakan hal yang sulit dipisahkan dari kehidupan sehari-hari. Tidak hanya berlaku bagi anak-anak, namun juga sampai remaja. Tujuan penelitian ini adalah untuk mengembangkan media pembelajaran berupa Permainan monopoli dikembangkan untuk perangkat smartphone android yang nantinya dapat di install. Diharapkan media pembelajaran ini dapat membantu siswa dalam belajar sehingga dapat meningkatkan hasil belajar siswa.

\section{Metode}

Penelitian dan pengembangan media pembelajaran telah dilaksanakan menggunakan metode Research and Development atau (R\&D). Penelitian pengembangan ini menggunakan model ADDIE yang memiliki lima tahapan sesuai dengan kepanjangan ADDIE menurut Reiser dan Mollenda yaitu analysis, design, development, implementation, evaluation (Karisma, Margunayasa, \& Prasasti, 2020; Kurniawan, Reyza, \& Taqwa, 2018; Siddiq, Sudarma, \& Simamora, 2020) Namun hanya dilaksanakan sampai tahap development saja dikarenakan kegiatan belajar mengajar pada siswa Sekolah Dasar masih dilaksanakan secara daring.

Instrumen yang digunakan dalam mengumpulkan data adalah angket. Data untuk uji validasi ahli media dan validasi ahli materi didapatkan dan dianalisis menggunakan teknik deskriptif presentase dan kategori untuk mengetahui kelayakan uji coba produk. Angka presentasi yang diperoleh selanjutnya dikelompokkan kedalam kriteria penilaian tabel berikut.

Tabel 1. Kriteria Penilaian Uji Validator Ahli

\begin{tabular}{cc}
\hline Skor & Kriteria \\
\hline $80-100 \%$ & Sangat Baik \\
$61-80 \%$ & Baik \\
$41-60 \%$ & Sedang \\
$21-40 \%$ & Kurang \\
\hline
\end{tabular}




\section{Hasil dan Pembahasan}

Langkah yang pertama yaitu studi pendahuluan. Studi pendahuluan merupakan tahap awal untuk mengembangkan media pembelajaran berupa Game Monopoli Asean untuk meningkatkan hasil belajar Tema 1 Selamatkan Makhluk Hidup pada Kelas 6 Sekolah Dasar. Pada tahap studi pendahuluan dilakukan melalui 3 objek yaitu studi pustaka, wawancara dan lapangan. Berdasarkan hasil wawancara dengan guru wali kelas 6 di SD Negeri Salatiga 03, pada saat pembelajaran, guru mengajar menggunakan alat peraga yang biasanya dipakai adalah alat peraga matematika seperti bangun ruang, bangun datar didampingi dengan alat ukur lain seperti penggaris dan busur. Dalam pemanfaatan mengoperasikan komputer guru-guru di SD Negeri Salatiga 03 masih sedikit awam. Untuk mencari materi atau video pembelajaran di youtube dan pembuatan lembar kerja masih bisa dilakukan, namun untuk membuat media yang menarik belum dilakukan sehingga pembelajaran menjadi monoton dan membosankan karena guru masih biasa menggunakan metode ceramah.

Langkah yang kedua yaitu penelitian dilakukan dengan model ADDIE. Model pengembangan ADDIE memiliki lima tahapan sesuai dengan kepanjangan ADDIE menurut Reiser dan Mollenda yaitu analysis, design, development, implementation, evaluation. Namun hanya dilaksanakan sampai tahap development saja dikarenakan kegiatan belajar mengajar pada siswa Sekolah Dasar masih dilaksanakan secara daring. Pada tahap pertama Analysis. Berdasarkan hasil wawancara oleh guru wali kelas 6 SD Negeri Salatiga 03, siswa memiliki karakter yang bervariasi, dapat dilihat ketika pembelajaran berlangsung dan ketika istirahat. Pada umumnya siswa memiliki karakter yang sopan, religius, toleransi, peduli lingkungan. Gaya belajar siswa di SD Negeri Salatiga 03, siswa mudah bosan saat kegiatan pembelajaran berlangsung karena guru masih menggunakan pembelajaran KTSP dengan metode ceramah untuk mencapai target dan tujuan pembelajaran kemudian memberi latihan soal. Sesuai karakter siswa kelas 6 yang masih suka bermain, pembelajaran menggunakan media yang inovatif seperti Game Monopoli Asean dapat menarik antusias peseta didik dalam belajar sambil bermain.

Tahap kedua yaitu Design, Pada tahap design dilakukan sebelum membuat penelitian untuk merancang media pembelajaran sama dengan merancang kegiatan belajar mengajar. Materi yang digunakan dalam pengembangan media pembelajaran Game Monopoli Asean yaitu materi tema 1. Selamatkan Makhluk Hidup, Subtema 1. Tumbuhan Sahabatku, Pembelajaran 1 kelas 6 Sekolah Dasar dengan mengunakan 3 mupel yaitu IPA, IPS, dan Bahasa Indonesia dengan materi Karaakteristik wilayah ASEAN dalam sosial budaya dan Perkembangbiakan generatif. Setelah menentukan rumusan Kompetensi Dasar dan Indikator kemudian menentukan tujuan pembelajaran. Adapun Tujuan pembelajaran dari muatan Bahasa Indonesia, IPA, dan IPS sebagai berikut : (1) Setelah membaca teks tentang ASEAN dan kehidupan sosial budaya dalam materi yang sudah di sedikan dalam Game Monopoli Asean, siswa dapat membedakan kehidupan sosial budaya dari dua negara ASEAN. (2) Dengan bermain Game Monopoli Asean, siswa dapat menjawab soal tentang perbedaan kehidupan sosial budaya di negara ASEAN. (3) Setelah membaca materi yang terdapat dalam Game Monopoli Asean, siswa dapat menentukan ide pokok dan informasi penting dalam materi. (4) Setelah membaca materi yang terdapat dalam Game Monopoli Asean, siswa dapat mengembangkan ide pokok dengan bahasanya sendiri. (5) Setelah membaca materi tentang bunga yang terdapat dalam Game Monopoli Asean, siswa dapat mengidentifikasi perkembangbiakan generatif. (6) Setelah membaca materi tentang bunga yang terdapat dalam Game Monopoli Asean, siswa dapat mengidentifikasi manfaat perkembangbiakan generatif.

Pada tahap ketiga yaitu Development, pada tahap ini dilakukan uji validitas ahli media dan uji validitas ahli materi untuk mengetahui tingkat kelayakan dari media Game Monopoli Asean untuk meningkatkan hasil belajar Tema 1 Selamatkan Makhluk Hidup pada Kelas 6 Sekolah Dasar dilakukan oleh ahli media pembelajaran. Validasi media dilakukan dengan memberikan rubrik instrumen media yang memiliki lima aspek yaitu tampilan secara menyeluruh, bahasa, cakupan isi, keterkaitan elemen satu sama lain, keseimbangan. Pada aspek tampilan secara menyeluruh terdapat tiga indikator yaitu media relevan dengan materi pembelajaran, jenis huruf pada teks mudah dibaca, ukuran huruf yang digunakan sudah sesuai dengan konten media. Pada aspek bahasa yang digunakan pada game terdapat dua indikator yaitu bahasa yang digunakan mudah dipahami, kemudahan dalam membaca tulisan pada game. Aspek yang tiga cakupan isi memiliki 3 indikator yakni kmenarikan isi game, penggunaan soal pada game, penggunaan soal pada game membantu penyampaian materi, alur atau aturan pada 
game mudah dipahami. Sedangkan pada aspek keterkaitan elemen satu sama lain memiliki dua indikator yakni aturan dan teks yang di sajikan pada game saling terkait, keterkaitan antar layout. Kemudian aspek yang terakhir aspek keseimbangan elemen media memiliki dua indikator yaitu keseimbangan besar kecilnya kartu pada game, keseimbangan tata letak kartu dan tulisan pada game. Jadi terdapat 12 indikator dengan skor maksimal 4 dan minimal 1 dari setiap indikator.

Tabel 3. Hasil Data Validasi Media

\begin{tabular}{ccc}
\hline Aspek & Skor ideal & Skor Aktual \\
\hline tampilan secara menyeluruh & 12 & 11 \\
bahasa yang digunakan & 8 & 7 \\
cakupan isi & 12 & 7 \\
keterkaitan elemen satu sama lain & 8 & 7 \\
keseimbangan elemen media & 8 & 8 \\
\hline Total & $\mathbf{4 8}$ & $\mathbf{4 0}$ \\
\hline
\end{tabular}

Penilaian yang diberikan oleh validator ahli media mmperoleh presentase sebesar $83 \%$ yang mennjukkan penilaian dengan kriteria sangat baik. Sedangkan, uji validasi materi pada media pembelajaran Game Monopoli Asean untuk meningkatkan hasil belajar Tema 1 Selamatkan Makhluk Hidup pada Kelas 6 Sekolah Dasar dilakukan oleh dosen Program Studi Sekolah Dasar. Validasi materi dilakukan dengan memberikan rubrik instrumen media yang memiliki 3 aspek yaitu kelayakan isi, bahasa, mendorong keingintahuan dan keaktifan. Pada aspek kelayakan isi memiliki 6 indikator yaitu kesesuaian dengan materi pelajaran, kesesuaian materi dengan konsep yang berlaku, penyajian materi, keterkaitan materi dengan tujuan pembelajaran, kelengkapan materi yang sesuai dengan perkembangan peserta didik, jumlah soal yang di berikan cukup. Sedangkan pada aspek bahasa yang digunakan pada materi memiliki 2 indikator yaitu kesesuaian penggunaan bahasa pada materi dengan tingkat perkembangan peserta didik, bahasa yang digunakan bersifat komunikatif. Kemudia yang terakhir aspek mendorong keingintahuan dan keaktifan memiliki 2 indikator yaitu siswa dapat lebih mudah memahami materi, siswa dapat lebih aktif dalam pembelajaran. Jadi terdapat 10 indikator dengan skor maksimal 4 dan minimal 1 dari setiap indikator. Penilaian yang diberikan oleh validator ahli materi mmperoleh presentase sebesar $78 \%$ yang mennjukkan penilaian dengan kriteria baik.

Tabel 4. Hasil Data Validasi Materi

\begin{tabular}{ccc}
\hline Aspek & Skor ideal & Skor Aktual \\
\hline kelayakan isi & 24 & 18 \\
aspek bahasa yang digunakan pada materi & 8 & 7 \\
aspek mendorong keingintahuan dan keaktifan & 8 & 6 \\
\hline Total & $\mathbf{4 0}$ & $\mathbf{3 1}$ \\
\hline
\end{tabular}

Pada tahap yang keempat yaitu Implementation, pada tahap ini seharusnya di uji coba tau dilaksanakan di Sekolah Dasar dikarenakan adanya covid-19 sehingga pembelajaran Sekolah Dasar dilaksanakan secara daring sehingga langkah yang keempat ini tidak bisa dilaksanakan pada siswa kelas 6 Sekolah Dasar. Spesifikasi Produk media pembelajaran berupa Game Monopoli Asean untuk meningkatkan hasil belajar Tema 1 Selamatkan Makhluk Hidup pada Kelas 6 Sekolah Dasar 


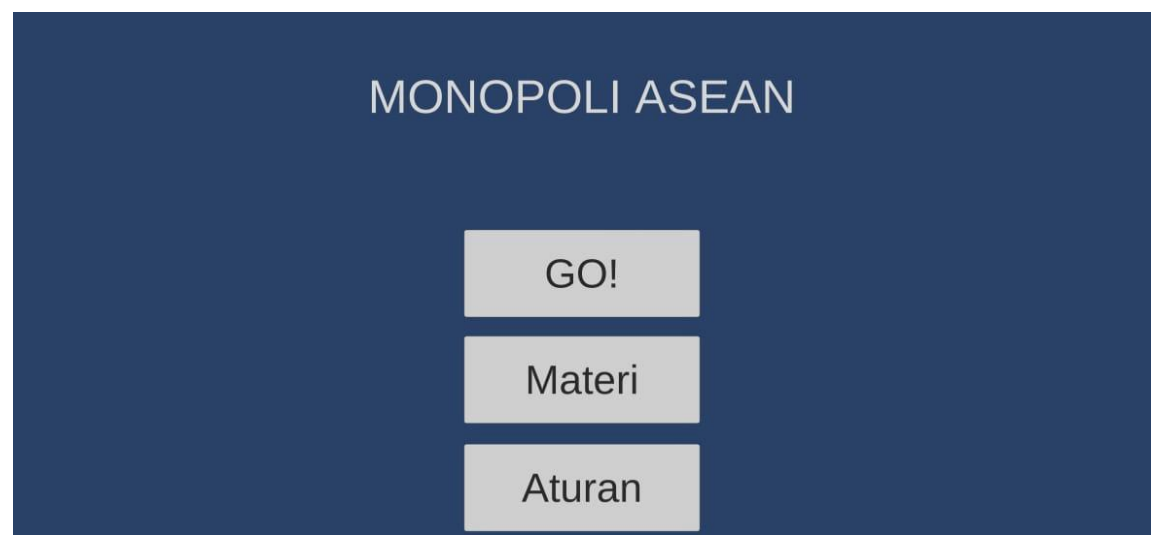

Gambar 1. Menu Home

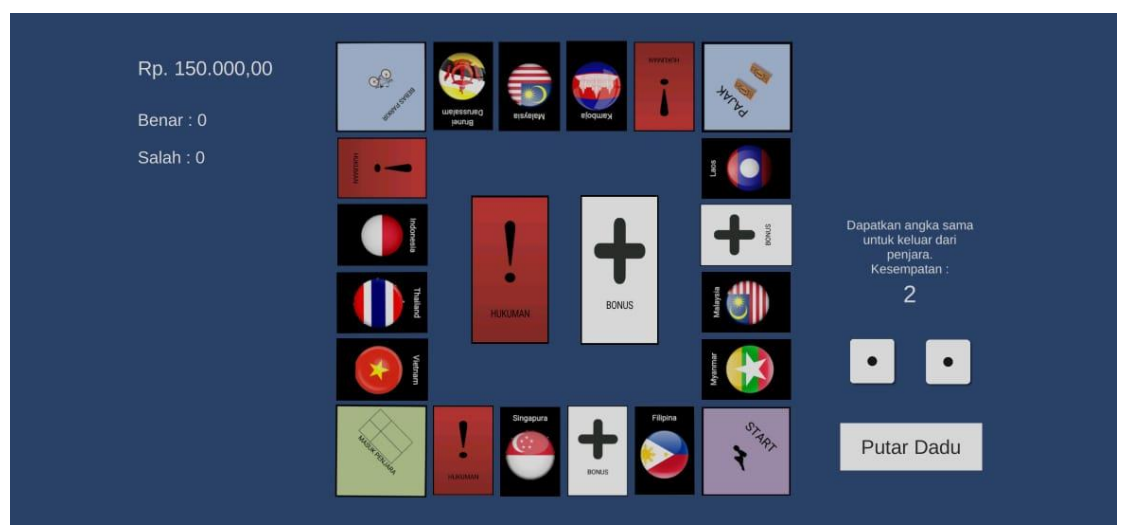

Gambar 2. Tampilan Permainan

Pada tahap Evaluation, Pada tahap revisi produk pengembangan media pembelajaran dilakukan setelah melakukan uji dan mendapatkan validasi dari ahli materi dan ahli media. Untuk uji validasi ahli media memperoleh presentase sebesar 83\% dengan kategori Sangat Baik. Namun ada saran dari ahli media yaitu untuk menambahkan gambar pada kartu negara pada monopoli. Sedangkan untuk uji validasi ahli materi memperoleh presentase sebesar 78\% dengan kategori Baik. Ada beberapa saran dari ahli materi yaitu pada bagian penyajian materi untuk menambah jumlah latihan soal. Media Game Monopoli Asean berbasis android dapat mendorong minat siswa dalam mempelajari tema 1, subtema 1, pembelajaran 1 Selamatkan Makhluk Hidup muatan Bahasa Indonesia, IPA, dan IPS dalam sebuah pemainan. Penggunaan Game Monopoli Asean dalam proses pembelajaran dapat memberikan warna baru dalam proses belajar mengajar sehingga dapat mendorong motivasi siswa dan menumbuhkan rasa ingin tahu siswa untuk memahami materi tema 1 , subtema 1, pembelajaran 1 Selamatkan Makhluk Hidup muatan Bahasa Indonesia, IPA, dan IPS kelas 6 Sekolah Dasar. Selain itu mdia Game Monopoli Asean berbasis android dapat menjadi salah satu referensi dan pandangan baru untuk guru membuat media pembelajaran yang lebih menarik dan lebih kreatif dalam mengembangkan media pembelajaran yang sesuai tujuan pembelajaran. Dapat disimpulkan bahwa media pembelajaran berupa Game Monopoli Asean dapat diterapkan pada siswa kelas 6 Sekolah Dasar. Hal tersebut disebabkan oleh beberapa faktor yaitu sebagai berikut.

Pertama, media pembelajaran yang dikembangkan berupa Game Monopoli Asean dapat diterapkan karena memudahkan siswa dalam memahami materi pelajaran. Media pembelajaran sangat berpengaruh dalam peningkatan hasil belajar siswa. Pembelajaran yang menarik menggunakan perangkat yang kreatif dan inovatif dalam proses pembelajaran lebih menyenangkan dengan media sehingga peserta didik lebih mudah mengingat mata pelajaran yang diajarkan oleh guru dengan media yang menarik (Naharir, Dantes, \& Kusmariyatni, 2019; Utami, Gede Agung, \& Sudiana, 2013; Wiastuti, Suadnyana, \& Kristiantari, 2014). Media pembelajaran yang dikemas secara menarik dan sesuai dengan materi pelajaran akan memudahkan siswa untuk memahami materi pelajaran dengan cepat. Selain itu, media pembelajaran yang dikembangkan juga berbentuk game sehingga siswa merasa 
tertantang dalam belajar. Pada dasarnya peserta didik itu menyukai sebuah permainan, maka dari itu untuk menarik perhatian peserta didik agar menyukai suatu pembelajaan harus menggunakan media yang menarik, bisa juga dengan media yang bisa sekaligus dibuat dengan bermain (Ependi, Panjaitan, \& Hutrianto, 2017; Gunarta, 2018). Siswa dapat belajar sambil bermain dapat sebagai alternatif belajar untuk menumbuhakan motivasi belajar peserta didik sehingga dapat lebih mudah utuk memahami materi dan bisa juga memperbaiki sikap siswa dalam kehidupan sehari-hari.

Kedua, media pembelajaran yang dikembangkan berupa Game Monopoli Asean dapat diterapkan karena membuat siswa tertarik dalam belajar. Validator media menilai produk media game monopoli asean dari 12 indikator, yaitu media relevan dengan materi pembelajaran, jenis huruf pada teks mudah di baca, ukuran huruf yang digunakan sudah sesuai dengan konten media, bahasa yang digunakan mudah dipahami, kemudahan dalam membaca tulisan pada game, kemenarikan isi game, penggunaan soal pada game membantu penyampaian materi, alur atau aturan pada game mudah dipahami, aturan dan teks yang di sajikan pada game saling terkait, keterkaitan antar layout, keseimbangan besar kecilnya kartu pada game, keseimbangan tata letak kartu dan tulisan pada game. Validator materi menilai produk media game monopoli asean dari 10 indikator, yaitu kesesuaian dengan materi pelajaran, kesesuaian materi dengan konsep yang berlaku, penyajian materi, keterkaitan materi dengan tujuan pembelajaran, kelengkapan materi yang sesuai dengan perkembangan peserta didik, jumlah soal yang di berikan cukup, kesesuaian penggunaan bahasa pada materi dengan tingkat perkembangan peserta didik. Selain itu bahasa yang digunakan bersifat komunikatif, siswa dapat lebih mudah memahami materi (Aspini, 2020; Masturah, Mahadewi, \& Simamora, 2018; Nida, Parmiti, \& Sukmana, 2020).

Penelitian yang dilakukan oleh Sartikaningrum (2013) menyatakna bahwa media pembelajaran permainan monopoli dapat meningkatkan motivasi siswa dalam belajar. Penelitian yang dilakukan oleh Putra, Wijayati, \& Mahatmanti (2017) didapatkan hasil kelayakan penggunaan media pembelajaran berbasis aplikasi android memiliki pengaruh sebesar 60,16\% terhadap hasil belajar, dan media pembelajaran berbasis android mendapat respon positif bagi siswa dengan hasil angket sebesar 80,05\%. Media pembelajaran berbasis android dapat meningkatkan hasil belajar. Dapat disimpulkan bahwa media pembelajaran yang telah diuji validitas dan mendapatkan kategori baik dapat digunakan oleh siswa untuk membantu siswa dalam belajar. Implikasi penelitian ini media ini dapat digunakan oleh guru untuk menciptakan suasana belajar baru yang menyenangkan sehingga dapat memudahkan siswa dalam memahami materi pembelajaran dan akan berpengaruh pada hasil belajar siswa yang meningkat.

\section{Simpulan}

Berdasarkan hasil uji dari ahli media pembelajaran dan materi pembelajaran media pembelajaran berupa Game Monopoli Asean mendapatkan kualifikasi sangat baik. Dapat disimpulkan bahwa media pembelajaran berupa Game Monopoli Asean dapat diterapkan untuk meningkatkan hasil belajar siswa kelas 6 Sekolah Dasar.

\section{Daftar Pustaka}

Asnur, \& Ambiyar. (2018). Penerapan Pembelajaran Menggunakan Media Video Pada Mata Kuliah Tata $\begin{array}{lllll}\text { Boga II. Mimbar Ilmu, } & \text { 23(3). }\end{array}$ https://doi.org/http://dx.doi.org/10.23887/mi.v23i3.16435

Aspini. (2020). Implementasi Pembelajaran PBL Berbantuan Media Kartu Soal Untuk Meningkatkan Kemampuan HOTS Pada Siswa Kelas VI SD. Jurnal Edutech Undiksha, 8(1), 72-79. Retrieved from https://ejournal.undiksha.ac.id/index.php/JEU

Awaludin, Wibawa, \& Winarsih. (2020). Integral Calculus Learning Using Problem Based Learning Model Assisted by Hypermedia-Based E-Book. Jurnal Pendidikan Indonesia, 9(2). https://doi.org/http://dx.doi.org/10.23887/jpi-undiksha.v9i2.23106

Azimi, Rusilowati, \& Sulhadi. (2017). Pengembangan Media Pembelajaran IPA Berbasis Literasi Sains untuk Siswa Sekolah Dasar. Pancasakti Science Education Journal, 2(2), 145-157. https://doi.org/http://doi.org/10.24905/psej.v2i2.754 
Effendi, H., \& Hendriyani, Y. (2020). The Conceptual and Hypothetical Model of Interactive Blended Problem Based Learning. JPI (Jurnal Pendidikan Indonesia), 8(2), 285. https://doi.org/10.23887/jpi-undiksha.v8i2.24162

Ependi, U., Panjaitan, F., \& Hutrianto, H. (2017). System Usability Scale Antarmuka Palembang Guide Sebagai Media Pendukung Asian Games XVIII. Journal of Information Systems Engineering and Business Intelligence, 3(2), 80. https://doi.org/10.20473/jisebi.3.2.80-86

Fathoni, Utomo, Hangga, \& Pamungkas. (2018). Pengembangan Media Pembelajaran Al-Qur'an Berbasis Android di TPQ Al-Falah Semarang. Edu Komputika Journal, 5(2). https://doi.org/https://doi.org/10.15294/edukomputika.v5i2.27165.

Gunarta, I. G. (2018). Pengaruh Model Pembelajaran TGT Berbantuan Media Question Card Terhadap Hasil Belajar IPA. Jurnal Pedagogi Dan Pembelajaran, 1(2). https://doi.org/http://dx.doi.org/10.23887/jp2.v1i2.19338

Hartini, S., Misbah, Dewantara, D., Oktovian, R. A., \& Aisyah, N. (2017). Developing learning media using online prezi into materials about optical equipments. Jurnal Pendidikan IPA Indonesia, 6(2), 313-317. https://doi.org/10.15294/jpii.v6i2.10102

Harususilo, Y. E. (2019). Skor PISA 2018: Daftar Peringkat Kemampuan Matematika, Berapa Rapor Indonesia? Kompas.Com.

Karisma, I. K. E., Margunayasa, I. G., \& Prasasti, P. A. T. (2020). Pengembangan Media Pop-Up Book pada Topik Perkembangbiakan Tumbuhan dan Hewan Kelas VI Sekolah Dasar. Jurnal Ilmiah Sekolah Dasar, 4(2), 121. https://doi.org/10.23887/jisd.v4i2.24458

Kurniawan, B. R., Reyza, M., \& Taqwa, A. (2018). Pengembangan Instrumen Tes Kemampuan Pemecahan Masalah Fisika pada Materi Listrik Dinamis. Jurnal Pendidikan: Teori, Penelitian, Dan Pengembangan, 3(11), 1451-1457.

Lestari, Negara, \& Ganing. (2017). Pengaruh Model Pembelajaran Word Square Berbantuan Media Lingkungan terhadap Kompetensi Pengetahuan IPA Siswa. MIMBAR PGSD Undiksha, 5(2), 9. https://doi.org/http://dx.doi.org/10.23887/jjpgsd.v5i2.10731

Lubis, \& Ikhsan. (2015). Pengembangan Media Pembelajaran Kimia Berbasis Android Untuk Meningkatkan Motivasi Belajar Dan Prestasi Kognitif Peserta Didik SMA. Jurnal Inovasi Pendidikan IPA, 1(2). https://doi.org/https://doi.org/10.21831/jipi.v1i2.7504.

Masturah, E. D., Mahadewi, L. P. P., \& Simamora, A. H. (2018). Pengembangan Media Pembelajaran PopUp Book pada Mata Pelajaran IPA Kelas III Sekolah Dasar. Jurnal EDUTECH Universitas Pendidikan Ganesha, 6(2),

212-221. https://doi.org/http://dx.doi.org/10.23887/jeu.v6i2.20294

Mulyadin. (2016). Implementasi Kebijakan Pembelajaran Tematik Terpadu Kurikulum 2013 Di SDN Kauman 1 Malang Dan Sd Muhammadiyah 1 Malang. Jurnal Pendidikan Edutama, 3(2), 31 - 48. https://doi.org/http://dx.doi.org/10.30734/jpe.v3i2.35

Muskania, R. T., Badariah, S., \& Mansur, M. (2019). Pembelajaran Tematik Menggunakan Media Video Scribe Pada Siswa Kelas IV Sekolah Dasar. Elementary: Islamic Teacher Journal, 7(1). https://doi.org/https://doi.org/10.21043/elementary.v7i1.4927

Mustikaningrum, G., Pramusinta, L., Ayu, S., \& Umar, M. (2020). Implementasi Pendidikan Karakter Terintegrasi Kurikulum Dan Metode Pembelajaran Pada Masa Pandemi Covid-19. AULADUNA: $\begin{array}{lllll}\text { Jurnal Pendidikan } & \text { Dasar } & \text { Islam, } & \text { 154-164. }\end{array}$ https://doi.org/https://doi.org/10.24252/10.24252/auladuna.v7i2a5.2020

Mustofa, R., \& Syafi'ah, R. (2018). Pengembangan Media Pembelajaran Pop Up Book Materi Kenampakan Permukaan Bumi Mata Pelajaran IPA Kelas III SD. ELSE (Elementary School Education Journal), 2, 30-41. https://doi.org/http://dx.doi.org/10.30651/else.v2i2.1723

Muyaroah, \& Fajartia. (2017). Pengembangan Media Pembelajaran Berbasis Android dengan menggunakan Aplikasi Adobe Flash CS 6 pada Mata Pelajaran Biologi. Innovative Journal of 
$\begin{array}{llc}\text { Curriculum } & \text { and } & \text { Educational } \\ \text { https://doi.org/https://doi.org/10.15294/ijcet.v6i2.19336. }\end{array}$

Technology.,

$6(2)$.

Naharir, R. A., Dantes, N., \& Kusmariyatni, N. (2019). Pengaruh Model Pembelajaran Course Review Horay Berbantuan Media Video Pembelajaran Terhadap Hasil Belajar Matematika Siswa Kelas V Semester Ii Sd Gugus Vi Kecamatan Sukasada. MIMBAR PGSD Undiksha, 7(1). https://doi.org/http://dx.doi.org/10.23887/jjpgsd.v7i1.16975

Nida, Parmiti, \& Sukmana. (2020). Pengembangan Media Kartu Bergambar Berorientasi Pendidikan Karakter Pada Mata Pelajaran Bahasa Bali. Jurnal EDUTECH Universitas Pendidikan Ganesha., 8(1), 16-31. 1 Retrieved from https://ejournal.undiksha.ac.id/index.php/JEU/article/view/25393/15846

Noviar, D. (2016). Pengembangan Ensiklopedi Biologi Mobile Berbasis Android Materi Pokok Pteridophyta Dalam Rangka Implementasi Kurikulum 2013. Cakrawala Pendidikan, 35(2). https://doi.org/https://doi.org/10.21831/cp.v15i2.8255

Nugraha, R. (2017). Evaluasi Penerapan Standar Penilaian Kurikulum 2013 Pada Kelas 4 Sekolah Dasar di Kecamatan Jambu. Jurnal Sekolah https://doi.org/https://doi.org/10.24114/js.v2i1.9925

Pramana, Jampel, \& Pudjawan. (2020). Meningkatkan Hasil Belajar Biologi Melalui E-Modul Berbasis Problem Based Learning. Jurnal Edutech Undiksha, 8(2), 18-32. https://doi.org/http://dx.doi.org/10.23887/jeu.v8i2.28921

Purbasari, R. julia, Kahfi, M. S., \& Yunus, M. (2013). Pengembangan Aplikasi Android sebagai Media Pembelajaran Matematika pada Materi Dimensi Tiga untuk Siswa SMA Kelas X. Jurnal Online Universitas Negeri Malang, 1-11. Retrieved from http://karyailmiah.um.ac.id/index.php/matematika/article/view/25844

Putra, R. S., Wijayati, N., \& Mahatmanti, F. W. (2017). Pengaruh Penggunaan Media Pembelajaran Berbasis Aplikasi Android Terhadap Hasil Belajar Siswa. Jurnal Inovasi Pendidikan Kimia, 11(2). Retrieved from https://journal.unnes.ac.id/nju/index.php/JIPK/article/view/10628

Qondias, Anu, \& Niftalia. (2016). Pengembangan Media Pembelajaran Tematik Berbasis Mind Mapping SD Kabupaten Ngada Flores. Jurnal Pendidikan Indonesia, 5(2), 176--182. https://doi.org/http://dx.doi.org/10.23887/jpi-undiksha.v5i2.8590

Qumillaila, Susanti, \& Zulfiani. (2017). Pengembangan Augmented Reality Versi Android Sebagai Media Pembelajaran Sistem Ekskresi Manusia. Cakrawala Pendidikan, 34(1), 57-69. Retrieved from https://journal.uny.ac.id/index.php/cp/article/view/9786/pdf. \%0A

Sartikaningrum, R. (2013). Pengembangan Media Pembelajaran Permainan Monopoli Akuntansi untuk Meningkatkan Motivasi Belajar Siswa Kelas X Program Keahlian Akuntansi SMK Negeri 1 Tempel. Universitas Negeri Semarang.

Siddiq, Sudarma, \& Simamora. (2020). Pengembangan Animasi Dua Dimensi Pada Pembelajaran Tematik Untuk Siswa Kelas III Sekolah Dasar. Jurnal Edutech Undiksha, 8(2), 49-63. https://doi.org/http://dx.doi.org/10.23887/jeu.v8i2.28928

Sofyan. (2016). Pembelajaran Problem Based Learning dalam Implementasi Kurikulum 2013 di SMK. $\begin{array}{llll}\text { Jurnal } \quad \text { Pondidikan } & \text { 6(3), }\end{array}$ https://doi.org/https://doi.org/10.21831/jpv.v6i3.11275

Suryanda, Ernawati, \& Maulana. (2016). Pengembangan Modul Multimedia Mobile Learning Dengan Android Studio 4.1 Materi Keanekaragaman Hayati Bagi Siswa Sma Kelas X. Jurnal Pendidikan Biologi, 9(1), 55-64. https://doi.org/https://doi.org/10.21009/biosferjpb.9-1.9

Tegeh, Simamora, \& Dwipayana. (2019). Pengembangan Media Video Pembelajaran Dengan Model Pengembangan 4D Pada Mata Pelajaran Agama Hindu. Jurnal Mimbar Ilmu, 24(2), 158-166. https://doi.org/http://dx.doi.org/10.23887/mi.v24i2.21262

Utami, S., Gede Agung, A. A., \& Sudiana, I. W. (2013). Pengaruh Model Experiential Learning 
Berbantuan Media Benda Asli Terhadap Hasil Belajar Ipa Siswa Kelas Iv Sd Gugus 1 Kecamatan Tabanan. Mimbar PGSD, 1(1). https://doi.org/http://dx.doi.org/10.23887/jjpgsd.v1i1.920

Wiastuti, Suadnyana, \& Kristiantari. (2014). Pengaruh Pembelajaran Siklus Belajar (Learning Cycle) Berbantuan Media Audio Visual Terhadap Hasil Belajar Ipa Siswa Kelas V Sd Gugus Budi Utomo. Mimbar PGSD Undiksha, https://doi.org/http://dx.doi.org/10.23887/jjpgsd.v2i1.2147

Wulandari, Sudatha, \& Simamora. (2020). Pengembangan Pembelajaran Blended Pada Mata Kuliah Ahara Yoga Semester II di IHDN Denpasar. Jurnal Edutech Undiksha, 8(1), 1-15. https://doi.org/http://dx.doi.org/10.23887/jeu.v8i1.26459 